\title{
TRPM2 Katyon kanallarının aktivasyonunda rol oynayan moleküler mekanizmalardaki son gelişmeler
}

\section{Recent developments on molecular mechanisms role on activation of TRPM2 cation channels}

Mustafa Saygın*a, Mustafa Nazıroğlu $b$,

a Süleyman Demirel Üniversitesi Tip Fakültesi, Fizyoloji AD, Isparta

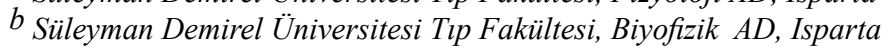

\begin{tabular}{|c|c|}
\hline MAKALE BİLGİLERİ & ÖZET \\
\hline Makale Geçmişi: & \multirow{11}{*}{$\begin{array}{l}\text { Transient receptor potential (TRP) kanalları ilk olarak } 1998 \text { yılında Drosophila türü sirke } \\
\text { sineklerinin göz hücrelerinde bulunmuştur. TRP kanallarının başlıca } 6 \text { familyası vardır. } \\
\text { Bunların da kendi aralarında alt grupları vardır. Örneğin, beyin ve nöron hücrelerinde } \\
\text { daha ziyade bulunan TRP Melastatindir. TRP kanalları (TRPM2) } \mathrm{Ca}^{2+} \text { için spesifik değil- } \\
\text { dir . TRPM kanallarının dört alt grubu vardır. Bu kanalların aktivasyon mekanizmaları ve } \\
\text { bulundukları organlar farklıdır. Özellikle oksidatif stres ürünleriyle aktive olabildiğinden } \\
\text { TRPM2 kanalları ile ilgilenmekteyiz. Oksidatif stres artışı ve antioksidan sistemin zayıf- } \\
\text { ladığı durumlarda DNA tahribi ve NAD den PARP ve sonrasında PARG aktivasyonları } \\
\text { ile ADP-Riboz (ADPR) oluşumu artmaktadır. Hem ADPR ve NAD hem de oksidatif stres } \\
\text { ürünlerinden olan } \mathrm{H}_{2} \mathrm{O}_{2} \text { nin TRPM2 kanallarını aktive ettiğine dair bildirimler mevcuttur. } \\
\text { Fakat bu kanalların oksidatif stres ve ADPR ile doğrudan veya dolaylı aktive olduğuna } \\
\text { dair zıt bildirimler mevcuttur. Günümüzde TRPM2 kanallarını doğrudan bloke eden kim- } \\
\text { yasal veya ilaç mevcut değildir. } \\
\text { J. Exp. Clin. Med., 2010; } 27: 42-45\end{array}$} \\
\hline $09 / 11 / 2009$ & \\
\hline $08 / 12$ / 2009 & \\
\hline * Yazışma Adresi: & \\
\hline Mustafa Saygın & \\
\hline Süleyman Demirel Üniversitesi Tıp & \\
\hline Fakültesi Fizyoloji AD, Morfoloji Binasi, & \\
\hline & \\
\hline Anahtar Kelimeler: & \\
\hline & \\
\hline TRPM2 katyon kanalı & \\
\hline
\end{tabular}

TrekM2 k

Elektrofizyoloji

Kalsiyum sinyali

ADP- Riboz

Oksidatif stres

\begin{abstract}
Transient receptor potential (TRP) channels were first described in Drosphila, where photoreceptor carrying trp gene mutations exhibit a transient voltage response to continuous light. These are subdivided into six major subgroups. Melastatin (or long) TRP channels (TRPM2) are nonspecific for $\mathrm{Ca}^{2+}$. We have become particularly interested in one member of latter family, known as TRPM2, for a number of reasons a potential role in cell death resulting from oxidative stress. Several mechanisms such as ADP-ribose (ADPR) and oxidative stres have been proposed for oxidant-mediated $\mathrm{Ca}^{2+}$ fluxes, including TRP channels. Activation of TRPM2 currents have been recorded upon exposure to ADPR as measured by $\mathrm{Ca}^{2+}$ influx using electrophysiological measurements in intact cells as well as in patch-clamp experiments. Additional experimental evidence from several groups shows that oxidative stress results in $\mathrm{Ca}^{2+}$ influx through TRPM2 opening, and consequently, $\mathrm{Ca}^{2+}$ dependent cell death. However, an important unanswered question is whether oxidantinduced gating of TRPM2 occurs directly at the membrane induced by $\mathrm{H}_{2} \mathrm{O}_{2}$ binding to TRPM2, or indirectly through production of the second messenger ADPR.
\end{abstract}

J. Exp. Clin. Med., 2010; 27: 42-45

C 2010 OMÜ Tüm Hakları Saklıdır.

\section{TRP Katyon Kanalları Ailesi}

Transient receptor potential (TRP) kanalları ilk olarak 1998 yılında Drosophila türü sirke sineklerinin göz hücrelerinde bulunmuştur (Clapham, 2003). Sonraları devam eden genetik araştırmalar neticesinde günümüzde 6 alt tipinin varlığı ispatlanmıştır. $\mathrm{Bu}$ alt tipleri; A) TRP cononcial (TRPC) 7 Farklı alt kanal grubu B) TRP vanilloid (TRPV) 6 Farklı alt kanal, C)
TRP polycystein (TRPP) 3 Farklı alt kanal, D) TRP mucolipin (ML) 3 Farklı alt kanal, E) TRP ankyrin (TRPA) 1 Farklı alt kanal, F) TRP melastatin (TRPM) 8 Farklı alt kanal grubu vardır. Bu iyon kanallarının çoğunluğu $\mathrm{Na}^{+}$ve $\mathrm{Ca}^{2+}$ a aynı anda geçirgen yani tek bir iyon kanalına seçici olmayan iyon kanallarıdır. Fakat bunun bazı istisnaları vardır. Bunlar TRPM4 ve TRPM5 monovalant katyonlara, TRPM6 ve TRPM7 
$\mathrm{Mg}^{+2}$ 'a geçirgen, TRPV5 ve TRPV6 ise $\mathrm{Ca}^{+2}$ 'a hayli geçirgendir (Nilius ve ark., 2007). TRPV1, TRPML6 ve TRPP3 ise $\mathrm{H}^{+}$a geçirgendir. TRPM alt familyasında başlıca 4 alt grup yer almaktadır. Birinci grupta TRPM1 ve TRPM3 yer almaktadır ve TRPM1'i aktive eden bilinmemektedir. TRPM3 $\mathrm{Ca}^{+2}$ ile aktive olmaktadır. İkinci grupta TRPM6 ve TRPM7 yer almaktadir ve TRPM6 ve TRPM7 $\mathrm{COOH}^{-}$terminal serin/treonin ile aktive olmaktadır. Üçüncü grupta TRPM4 ve TRPM5 yer almaktadır ve TRPM4 ve TRPM5 $\mathrm{Ca}^{+2}$ 'a geçirgen değildir. Dördüncü grupta TRPM2 ve 8 yer almaktadır ve TRPM2 NUDT9 ucu ADP-Riboz ve oksidatif stres ve 1sı ile aktive olurken TRPM8 soğuk reseptörüyle aktive olmaktadır (Miller, 2006; Birnbaumer, 2009). Bu derleme içerisindeki yazarlar olarak, oksidatif stres ve ADP-riboz (ADPR) ile aktive olmalarından dolayı TRPM2 kanalları ile ilgilenmekteyiz.

\section{TRPM2 kanalları}

TRPM2 katyon kanallarında da diğer iyon kanallarında olduğu gibi 6 segment bulunmaktadır ve iyon akışı 5 . ve 6 . segmentler arasından gerçekleşmektedir (Nilius ve ark., 2007). Kanalın N ve C olmak üzere iki ucu bulunmaktadır. Yakın zamanda yapılan çalışmalar, N-terminal bölgeyi kapsayan bir düzenleyici alan protein çevirmesi ve/veya trafiği çevirebildiğini önermektedir. $\mathrm{C}$ ucuna nudix domain denilmektedir. Bu uçta ADPR pirofosfataz enzimi vardır. Bu enzim, ADPR'dan AMP ve Ribose 5-fosfat oluşumunu katalizlemektedir (Clapham, 2007).

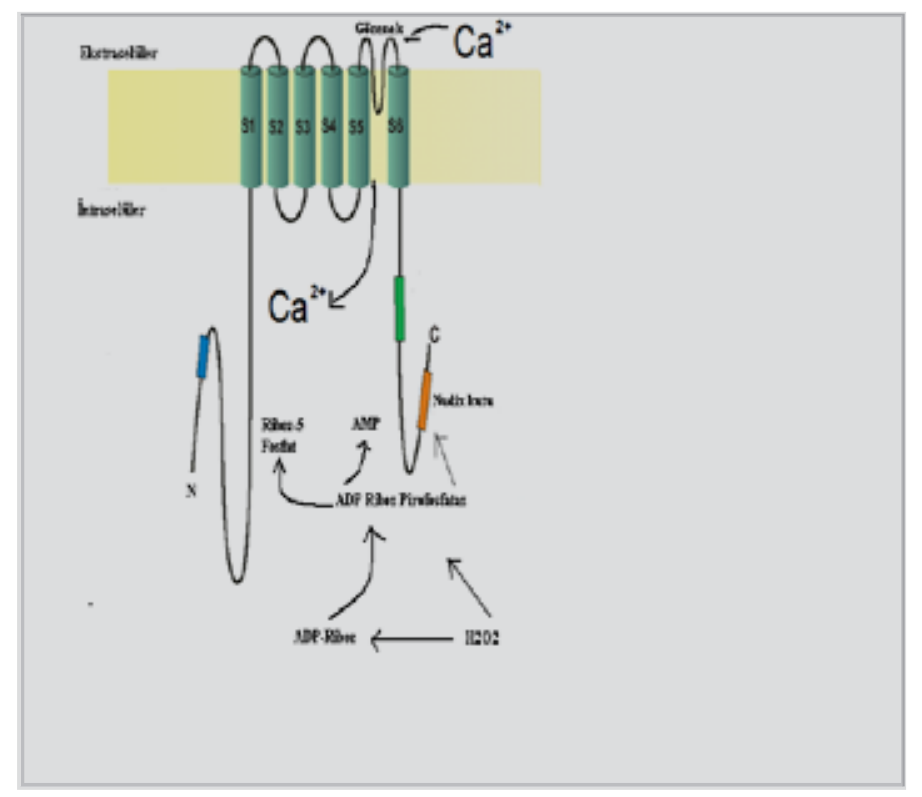

Şek. 1: TRPM2 kanalının moleküler yapısı (Clapham, 2007).

\section{Oksidatif stres ve ADPR}

Reaktif oksijen türleri (ROS) şunlardır; superoksit radikali, hidrojen peroksit ve hidroksil ra- dikali gibi hemoglobin poliansatüre yağ asitleriyle otooksidasyonla sürekli üretilir (Miller, 2006). Lipid peroksidasyonu hücre yaralanmasına intraselüler zar ve hücre yıkılmasina sebep olabilir ve sonradan hücre ölümüne sebep olur (Akyol ve ark., 2004; Halliwell, 2006; Naziroglu, 2007; Kovacic ve Somathan, 2008). Hücrelerde çeşitli antioksidan mekanizmaları ROS'un zararlı etkilerine sebep olur, ancak hipoksiyle antioksidan mekanizmaların verimliliğinin kaybı ve mitokondrial elektron sisteminde serbest radikal oluşumunda artış olur (Altindag ve Celik, 2006; Naziroglu, 2007). Glutatyon peroksidaz (GSH-Px) enzimi hidrojen peoksiti suya kadar parçalar. GSH-Px aynı zamanda organik hidroperoksidazı ortadan kaldırabilir (Kovacic ve Somathan, 2008). GSH hücre fonksiyonlarının geniş bölgesinde bir hidroksil radikali ve tekli oksijen çöpçüsüdür (Rayman, 2000). Vitamin E ( $\alpha$-tokoferol) hücrelerin lipid fazında çok önemli bir antioksidandır. Vitamin E serbest radikallerin etkilerine karşı, vücudun metabolizması tarafindan üretilen potansiyel zarara karşı hücreleri korumada rol oynar (Naziroglu, 2007). Vitamin C (askorbik asit), sivı faz serbest radikal çöpçüsüdür, aynı zamanda vitamin E' yi aktif forma dönüştürür (Frei ve ark., 1989).

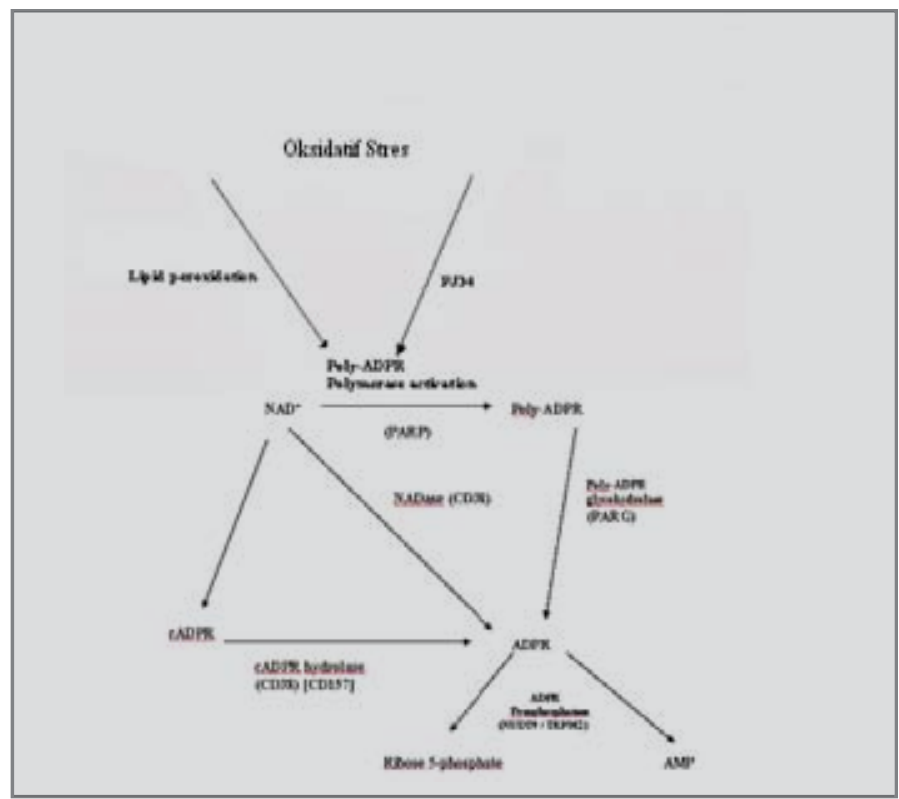

Şek. 2: Oksidatif stresin ADPR oluşumunu katalizleme yolları. ADPR başlıca 3 yolla sentezlenmektedir. 1- NAD ${ }^{+}$, poliADPR polimeraz (PARP) enzimi (PARP-1 den PARP-18 e kadar çeşitleri vardır) vasıtası ile poliADPR oluşur, bundanda poliADPR glikohidrolaz enzimi vasıtası ile ADPR oluşturulur. 2- NAD ${ }^{+}$, cADPR'ye daha sonra cADPR hidrolaz vasıtasıyla ADPR oluşturulur. 3- $\mathrm{NAD}^{+}$'dan NADaz enzimi vasıtası ile ADPR oluşturulur. Bu üç mekanizmayı da oksidatif stres ürünlerinden olan ROS ve nitrojen oksidatif stres (NOS) ürünleri aktive etmektedir (Naziroglu, 2007, Szabo, 2005).

\section{ADPR ve Oksidatif Stres Tarafindan TRPM2 Katyon Kanalı Açılması}

TRPM2 ağırlıklı olarak beyinde varlığı ispatlanmasına rağmen, aynı zamanda kemik iliği, dalak, kalp, lökosit, karaciğer ve akciğeri kapsayan diğer 
birçok dokularda saptanabilir. 2001'li yılların başlangicında Perraud ve ark., (2001) tarafindan TRPM2 kanallarının ADPR tarafından aktive olabildikleri ilk defa gösterilmiştir. 2002 yılında Aachen Tıp Fakültesi Fizyoloji Enstitüsündeki Lückhoff'un grubu ile (Wehage ve ark., 2002; Naziroglu ve ark., 2008), Japonyadan Hara ve ark., (2002) yaptıkları çalışmalarda TRPM2 kanallarının oksidatif stresle aktive olabile-

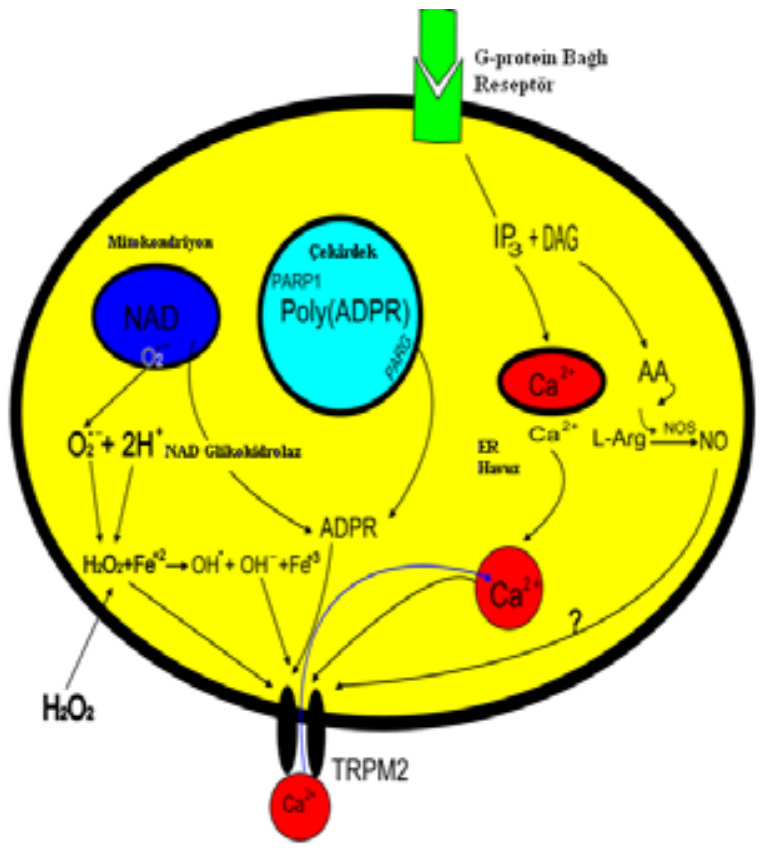

Şek. 3: ADPR ve TRPM2 kanal aktivasyonu ile oksidatif stres arasındaki ilișkinin şematik sunumu. ADPR üretimi G proteine bağlı reseptörlere ligand kanal aktivasyonu ile başlatılır. Reseptör aktivasyonu aynı zamanda intrasellüler $\mathrm{Ca}^{+2}$ yoğunluğunun yükselmesi IP3 tarafindan hücre içi organellerden $\mathrm{Ca}^{+2}$ serbest bırakılmasını sağlar. TRPM2 hücreye doğru güçlenen TRPM2 aktivasyonuyla bir pozitif feed back ile $\mathrm{Ca}^{+2}$ girişi sağlar. Alternatif kaynaklar ADPR içeren mitokondri ve çekirdektir. ADPR polimerlerinin stimülasyon sonras1 poli (ADPR) polimeraz-1 (PARP-1)'e ve sonrasinda poly (ADPR) glikohidrolaz (PARG) tarafından ADPR'ye hidroliz edilir. Bu olay hücreyi apoptozise gidinceye kadar uyarabilir. Sitozolde $\mathrm{Ca}^{+2}$ artışı mitokondride depolarizasyon ve porların açılması veya hücre dışından sitozole $\mathrm{H}_{2} \mathrm{O}_{2}$ lerin gelişi daha fazla nitrik oksit sentaz (NOS) ve ROS üretilir. ADPR ve ROS geri bildirim mekanizması ile TRPM2 kanallarının açılması yolu ile sitozole $\mathrm{Ca}^{+2}$ akışını artırır (Naziroglu, 2007). ceği ispatlanmıştır. Daha sonraları yapılan çalışmalarda, araştırmacılar etki mekanizmasının doğrudan ve dolaylı yolları konusunda iki gruba ayrılmışlardır. Bir kısım araştırmacılar (Perraud ve ark., 2005) oksidatif stresin mitokondriden ADPR üretimini artırdığını ve ADPR'nin TRPM2 kanallarını açtığını öne sürerken diğer bir kısım araştırmacılar (Hara ve ark., 2002; Wehage ve ark., 2002; Naziroglu, 2007; Naziroglu, 2007) hem oksidatif stresin hemde ADPR'nin birbirinden bağımsız olarak kanalları açabildiklerini ispatlamışladır. $\mathrm{Bu}$ son bildirim, bizim grubumuzun tekli kanal kayıtları ile ispatlanmıştır (Naziroglu ve Lückhoff, 2008). Aynı zit bildirimler cADPR hakkında da söz konusudur. Yakın zamanda yapılan çalışmalarda Gasser ve ark., (2006) T lenfositlerinde TRPM2 kanallarının cADPR ile aktive olduğunu rapor ederken, Heiner ve ark., (2006) nötrofil granülositlerde cADPR' nin TRPM2 kanallarının aktivasyonunda etkisinin olmadığını bildirmişlerdir. Bu çalışmalarda farklı sonuçların gözlenilmesi, farklı tip hücrelerin kullanılmasına bağlanmaktadır.

\section{Sonuc}

TRPM2 kanallar1 hem oksidatif stres hemde ADPR ile aktive olabilmektedir. Günümüzde doğrudan bu kanalları kapatan bir kanal blokörü mevcut değildir. Ayrıca, mevcut $\mathrm{Ca}^{+2}$ kanal blokörleri de bu kanalları bloke edememektedir. Patch-clamp çalışmaları önderliğinde TRPM2 kanallarını doğrudan bloke eden maddelerin araştırılması önem arz etmektedir. TRPM2 kanallarındaki genetik bozukluklarının değişik nörolojik hastalıkların etiyolojisindeki rolünün araştırılması gerekmektedir. Ayrıca, TRPM2 kanallarını bloke eden kimyasal veya ilaçların en yakın zamanda bulunması birçok nörolojik hastalıkların tedavisinde fayda sağlayacaktır.

\section{KAYNAKLAR:}

Akyol, O., Zoroglu, S.S., Armutcu, F., Sahin, S., Gurel, A. 2004. Nitric oxide as a physiopathological factor in neuropsychiatric disorders. In Vivo. 18, 377-390.

Altindag, O., Celik, H. 2006. Total antioxidant capacity and the severity of the pain in patients with fibromyalgia. Redox Rep. 11, 131-135.

Birnbaumer, L. 2009. The TRPC class of ion channels: a critical review of their roles in slow, sustained increases in intracellular $\mathrm{Ca}(2+)$ concentrations. Annu Rev. Pharmacol. Toxicol. 49, 395-426.

Clapham, D.E. 2003.TRP channels as cellular sensors. Nature. 426, 517-524.

Clapham, D.E. 2007. Snapshot: mammalian TRP channels. Cell. 129, 220.

Frei, B., England, L., Ames, B.N., 1989. Ascorbate is an outstanding antioxidant in human blood plasma. Proc. Natl. Acad. Sci. USA. 86, 6377-6381.

Gasser, A., Glassmeier, G., Fliegert, R., Langhorst, M.F., Meinke, S., Hein, D., Kruger, S., Weber, K., Heiner, I., Oppenheimer, N., Schwarz, J.R., Guse, A.H. 2006. Activation of T cell calcium influx by the second messenger ADP-ribose. J. Biol. Chem. 281, 2489-2496.

Halliwell, B. 2006. Oxidative stress and neurodegeneration: where are we now? J. Neurochem. 97, 16341658. 
Hara, Y., Wakamori, M., Ishii, M., Maeno, E., Nishida, M., Yoshida, T., Yamada, H., Shimizu, S., Mori, E., Kudoh, J., Shimizu, N., Kurose, H., Okada, Y., Imoto, K., Mori, Y. 2002. LTRPC2 $\mathrm{Ca}^{2+}$-permeable channel activated by changes in redox status confers susceptibility to cell death. Mol. Cell. 9, 163-73.

Heiner, I., Eisfeld, J., Warnstedt, M., Radukina, N., Jungling, E., Luckhoff, A. 2006. Endogenous ADP-ribose enables calcium-regulated cation currents through TRPM2 channels in neutrophil granulocytes. Biochem. J. 398, 225-232.

Kovacic, P., Somanathan, R. 2008. Unifying Mechanism for Eye Toxicity: Electron Transfer, Reactive Oxygen Species, Antioxidant Benefits, Cell Signaling and Cell Membranes. Cell Membr. Free Radic. Res. 2, 56-69.

Miller, B.A. 2006, The role of TRP channels in oxidative stress-induced cell death. J. Membr. Biol. 209, 3141.

Naziroglu, M. 2007. Molecular Mechanisms of vitamin E on intracellular signaling pathways in brain. In: Reactive Oxygen Species and Diseases. Ed.; Laszlo Goth, Research Signpost Press: Kerala, India. 239-256.

Naziroglu, M., Lückhoff, A. 2008. Effects of antioxidants on calcium influx through TRPM2 channels in transfected cells activated by hydrogen peroxide. J. Neurolog. Sci. 15, 152-158.

Naziroglu, M., Lückhoff, A. 2008. A calcium influx pathway regulated separately by oxidative stress and ADP- ribose in TRPM2 channels: Single channel events. Neurochem. Res. 33, 1256-1262.

Naziroglu, M. 2007. New molecular mechanisms on the activation of TRPM2 channels by oxidative stress and ADP-ribose. Neurochem. Res. 32, 1990-2001.

Nilius, B., Owsianik, G., Voets, T., Peters, J,A. 2007. Transient Receptor Potential cation channels in disease. Physiol. Rev. 87, 165-217.

Perraud, A.L., Fleig, A., Dunn, C.A., Bagley, L.A., Launay, P., Schmitz, C., Stokes, A.J., Zhu, Q., Bessman, M.J., Penner, R., Kinet, J.P., Scharenberg, A.M. 2001. ADP-ribose gating of the calcium-permeable LTRPC2 channel revealed by Nudix motif homology. Nature. 411, 595-599.

Perraud, A.L., Takanishi, C.L., Shen, B., Kang, S., Smith, M.K., Schmitz, C., Knowles, H.M., Ferraris, D., Li, W., Zhang, J., Stoddard, B.L., Scharenberg, A.M. 2005. Accumulation of free ADP-ribose from mitochondria mediates oxidative stress-induced gating of TRPM2 cation channels. J. Biol. Chem. 280, 6138-6148.

Rayman, M.P. 2000. The importance of selenium to human health. Lancet. 356, 233-241.

Szabo, C. 2005. Roles of poly (ADP-ribose) polymerase activation in the pathogenesis of diabetes mellitus and its complications. Pharmacol. Res. 52, 60-71.

Wehage, E., Eisfeld, J., Heiner, I., Jüngling, E., Zitt, C., Lückhoff, A. 2002. Activation of the cation channel long transient receptor potential channel 2 (LTRPC2) by hydrogen peroxide. A splice variant reveals a mode of activation independent of ADP- ribose. J. Biol. Chem. 277, 23150-23156. 